\title{
Statin use and mortality of patients with prostate cancer: a meta-analysis
}

This article was published in the following Dove Press journal:

OncoTargets and Therapy

21 March 2016

Number of times this article has been viewed

\author{
Yang Mengl,* \\ Yan-Biao Liao $2, *$ \\ Peng $X u^{\prime}$ \\ Wu-Ran Wei' \\ Jia Wang'
}

'Department of Urology, ${ }^{2}$ Department of Cardiology, West China Hospital of Sichuan University, Chengdu, People's Republic of China

*These authors contributed equally to this work
Correspondence: Jia Wang Department of Urology, West China Hospital, Sichuan University, 37 Guo Xue Xiang, Chengdu 61004I, People's Republic of China

Tel +86 I36 840575 I2

Fax +862885501670

Email jiawangl4|4@sina.com
Objective: The aim of this meta-analysis was to investigate the effect of statin use on the mortality of patients with prostate cancer $(\mathrm{PCa})$.

Methods: An electronic search of PubMed, Embase, and CENTRAL databases from inception to August 2015 was performed to find eligible studies. Articles investigating the association between statin use and mortality of PCa were identified. Pooled hazard ratios (HRs) and 95\% confidence intervals (CIs) were calculated using random- or fixed-effects models.

Results: In total, 13 studies that enrolled 100,536 participants were included in this metaanalysis. Results showed that prediagnostic statin use had a significantly lower risk of both all-cause mortality (ACM; HR, 0.56; 95\% CI, 0.38-0.83) and PCa-specific mortality (PCSM; HR, 0.53 ; 95\% CI, 0.36-0.77). Similarly, postdiagnostic statin use was correlated with reductions in both ACM (HR, 0.77; 95\% CI, 0.69-0.87) and PCSM (HR, 0.64; 95\% CI, 0.52-0.79). When stratified by primary treatment, postdiagnostic use of statins had a 0.4 -fold lower risk of ACM in patients with PCa who were treated with local therapy; both pre- and postdiagnostic use of statins was correlated with a significantly lower risk of PCSM in patients who were treated with androgen deprivation therapy.

Conclusion: Both pre- and postdiagnostic use of statins is associated with better overall survival and PCa-specific survival. This suggests a need for randomized controlled trials of statins in patients with $\mathrm{PCa}$.

Keywords: prostate cancer, all-cause mortality, prostate cancer-specific mortality, statins

\section{Introduction}

Statins (3-hydroxy-3-methylglutaryl coenzyme A reductase inhibitors) are commonly used to treat hypercholesterolemia and have been demonstrated to reduce cardiovascular events and mortality. ${ }^{1}$ Most recently, attention has focused on their potential anticancer properties. Statins have been shown to affect proliferation, induce apoptosis, and inhibit angiogenesis of tumor cells. ${ }^{2-4}$ Several epidemiological studies have investigated the effects of statins on the risk of prostate cancer (PCa) and treatment outcomes. A recent meta-analysis of 27 observational studies revealed that statins reduced the risk of both overall $\mathrm{PCa}$ and clinically important advanced $\mathrm{PCa} .{ }^{5}$ However, the impact of statins on all-cause mortality (ACM) or PCa-specific mortality (PCSM) in patients with PCa remains debatable. Some studies have demonstrated a beneficial effect of statins in reducing ACM and PCSM, ${ }^{6-8}$ whereas others have not revealed a significant effect. ${ }^{9,10}$ These inconsistent conclusions may be due to relatively small sample sizes and different timings of statin use (eg, prediagnostic or postdiagnostic). Therefore, we performed a systematic review and meta-analysis of the available data to explore the association of prediagnostic and postdiagnostic statin use with the risk of death in patients with PCa. 


\section{Materials and methods Search strategy}

An electronic search of PubMed, Embase, and CENTRAL databases for all relevant studies (the last search update was August 21, 2015) was carried out using the following search terms: "Hydroxymethylglutaryl-CoA Reductase Inhibitors or HMG-CoA Reductase Inhibitors or statin or statins or atorvastatin or bervastatin or cerivastatin or crilvastatin or compactin or dalvastatin or fluindostatin or fluvastatin or glenvastatin or lovastatin or mevastatin or pitavastatin or pravastatin or rosuvastatin or simvastatin or tenivastatin" and "prostate cancer or prostate carcinoma or prostatic cancer or prostatic carcinoma" and "mortality or survival or death." The search was limited to English language articles. All searches were performed independently by two investigators and any differences were resolved by discussion.

\section{Selection criteria}

Following the Preferred Reporting Items for Systematic Reviews and Meta-analysis guidelines, the Population, Intervention, Comparison, Outcome, and Study design eligibility criteria were applied to define study eligibility. ${ }^{11}$ All studies investigating the association between statin use and mortality of $\mathrm{PCa}$ were considered relevant to this meta-analysis. Both full-text articles and conference abstracts were eligible. Inclusion criteria were as follows: 1) the exposure of interest was statin use prior to or after diagnosis, 2) ACM and/ or PCSM after PCa diagnosis according to statin use were reported, and 3 ) adjusted risk estimates with $95 \%$ confidence intervals (CIs; or adjusted risk estimates and $P$-values) were given. Case reports, letters, review articles, and comments were excluded during the process of study selection. For studies that reported results using the same or overlapping data, only the study with the largest number of patients was included.

\section{Study quality assessment}

All the finally included studies were nonrandomized studies. The quality of all studies, except the conference abstracts, was assessed according to the Newcastle-Ottawa scale, ${ }^{12}$ which is recommended by the Cochrane Collaboration. Stars were allocated to each study in the range of $0-9$, and studies with 6 or more stars were deemed of high quality.

\section{Data extraction}

Two authors (YM and JW) independently extracted the data from all the included studies, and the following information was extracted: the first author, year of publication, study location, sample size, follow-up period, patient characteristics (eg, age, pretreatment prostate-specific antigen level, tumor stage, and Gleason score), type of primary treatment, statin use, risk estimates with their corresponding 95\% CIs (or $P$-values), and study design. Any discrepancy was resolved by discussion.

\section{Statistical analyses}

The inverse variance method was used to pool the hazard ratios (HRs) for the effect of statin on mortality in patients with PCa. ${ }^{13}$ Because outcomes were relatively rare, odds ratio (OR) was used as an estimate of $\mathrm{HR}$. If studies reported risk estimates for PCSM and other-cause mortality, the risk estimates for ACM were calculated first. ${ }^{14}$ For any study providing separate risk estimates by primary treatment, we considered the estimates as different studies. ${ }^{6}$ Between-study heterogeneity was assessed using both Cochran's $Q$-test and $I^{2}$ statistics. A value of $P<0.10$ for $Q$-test or an $I^{2}>50 \%$ was considered significant. A random-effects model was used if heterogeneity was significant; otherwise, a fixed-effects model was used. ${ }^{15}$ Subgroup analyses were conducted to explore potential sources of between-study heterogeneity. The potential publication bias was assessed by funnel plot visual inspection for all comparisons. All statistical analyses were performed with RevMan software (version 5.3). $P$-values for all analyses were two sided.

\section{Results}

\section{Characteristics of eligible studies}

In total, 401 abstracts were identified and assessed from the initial literature search, and 24 studies were potentially eligible and were evaluated in detail. Eleven of the 24 studies were subsequently excluded from the present meta-analysis (nine did not fulfill the inclusion criteria and two were based on overlapping data). Thus, 13 studies (12 cohort studies and one case-control study) involving 100,536 participants were included in the meta-analysis. ${ }^{6-10,14,16-22}$ The flow chart of the study selection is shown in Figure 1.

Of the 13 studies, six investigated the association of prediagnostic statin use with ACM and/or PCSM, and seven investigated the association of postdiagnostic statin use with ACM and/or PCSM. The characteristics and quality assessments of eligible studies are summarized in Table 1. Visual inspection of funnel plots did not reveal any obvious publication bias in our meta-analysis.

\section{ACM}

Eight studies $6,9,14,17,19-22$ that met the inclusion criteria were included in the analysis of ACM: two focused on statin use 


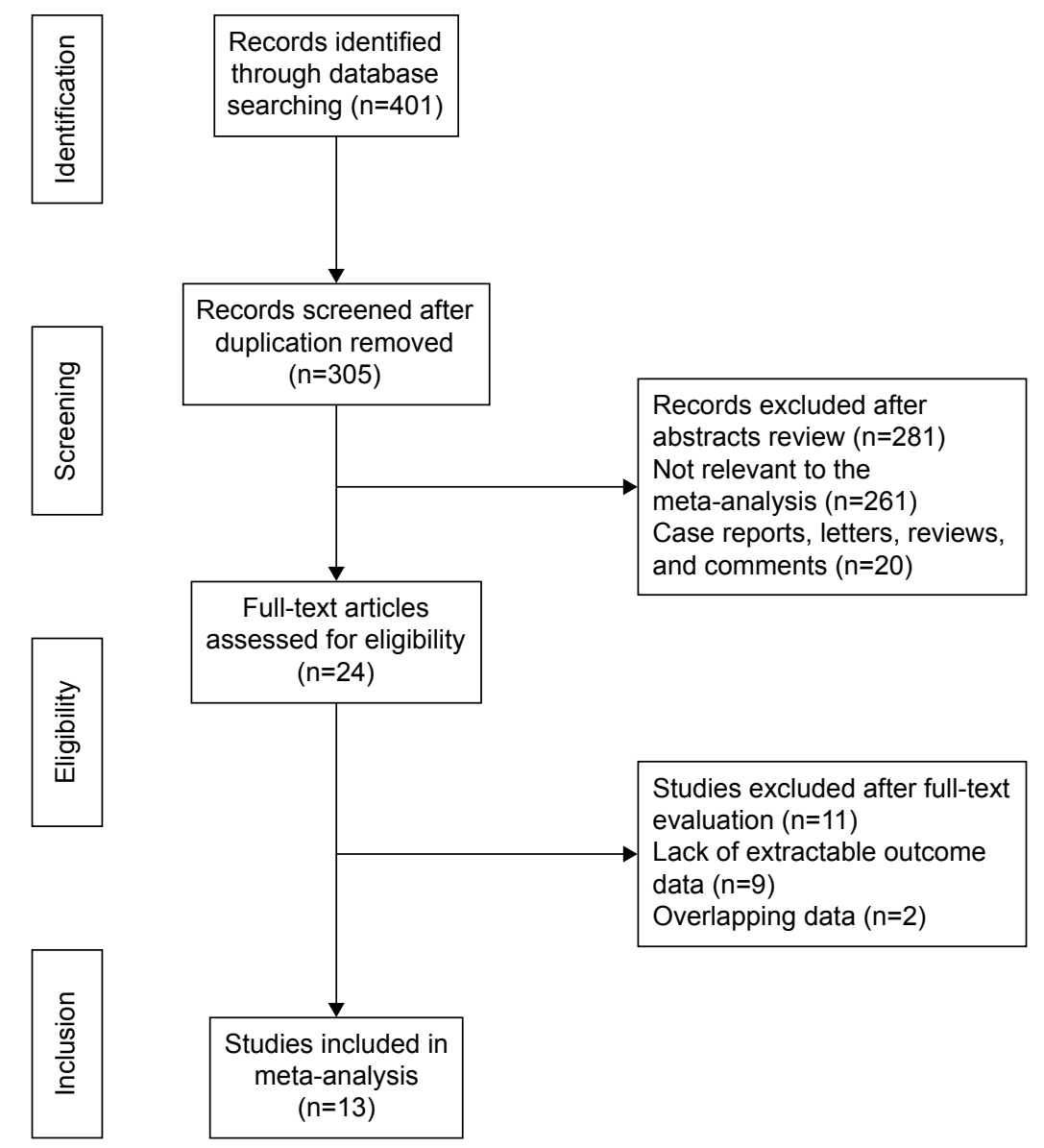

Figure I Flow diagram of the study selection process.

before diagnosis and six focused on statin use after diagnosis. The pooled risk estimates are shown in Table 2 and Figure 2. Both pre- (HR, 0.56; 95\% CI, 0.38-0.83; $P<0.01 ; I^{2}=0 \%$ ) and postdiagnostic use of statin (HR, 0.77; 95\% CI, 0.69-0.87; $P<0.01 ; I^{2}=72 \%$ ) was associated with a significantly reduced risk of ACM in patients with $\mathrm{PCa}$.

Subgroup analysis according to the treatment strategy was then performed. Postdiagnostic statin use was significantly correlated with a decreased risk of ACM among patients with PCa who were primarily treated with local therapy (radical prostatectomy or radiotherapy; HR, 0.46; 95\% CI, 0.28-0.77; $P<0.01 ; I^{2}=53 \%$ ). A pooled analysis of three studies failed to distinguish primary treatment used and also revealed that postdiagnostic statin use was associated with lower ACM (HR, 0.81; 95\% CI, 0.77-0.84; $P<0.01 ; I^{2}=22 \%$ ).

\section{PCSM}

In total, ten studies $7,8,10,14,16-20,22$ were included in the analysis of PCSM: six were based on prediagnostic statin use and four on postdiagnostic statin use. The pooled risk estimates are shown in Table 2 and Figure 3.
The results demonstrated that patients who used statins before diagnosis had a 0.5 -fold lower risk of PCSM (HR, 0.53 ; 95\% CI, 0.36-0.77; $P<0.01 ; I^{2}=77 \%$ ). When stratified by primary treatment, prediagnostic statin use was still associated with a decreased risk of PCSM among patients who were treated with androgen deprivation therapy (HR, 0.53 ; 95\% CI, 0.29-0.98; $P=0.043)$. The pooled risk estimate from studies that did not distinguish primary treatment was also correlated with a significantly lower risk of PCSM (HR, 0.44; 95\% CI, 0.20-0.95; $P=0.04 ; I^{2}=88 \%$ ), whereas prediagnostic statin use among patients who were primarily treated with local therapy showed only a trend toward decreased risk ( $\mathrm{HR}, 0.52 ; 95 \% \mathrm{CI}, 0.17-1.58$; $P=0.25 ; I^{2}=61 \%$ ).

Similarly, a significant correlation of postdiagnostic statin use with a reduced risk of PCSM was found (HR, 0.64; 95\% CI, $0.52-0.79 ; P<0.01 ; I^{2}=79 \%$ ). When stratified by primary treatment, postdiagnostic statin use was associated with a significantly decreased risk of PCSM in patients who were treated with androgen deprivation therapy (HR, 0.64; 95\% CI, 0.48-0.86; $P=0.003$ ). A pooled analysis of those studies could not distinguish primary treatment (HR, 0.73; 95\% CI, 


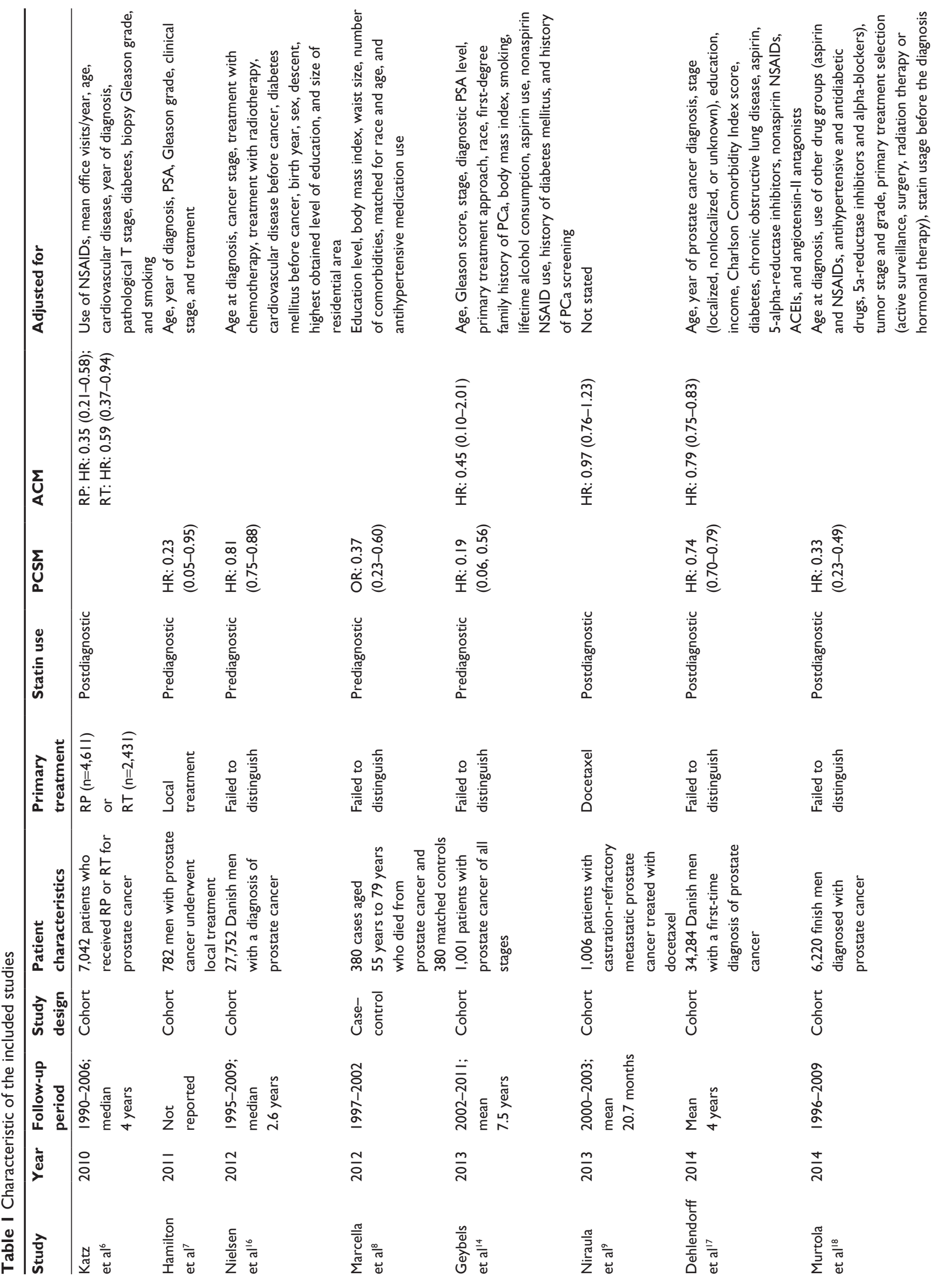



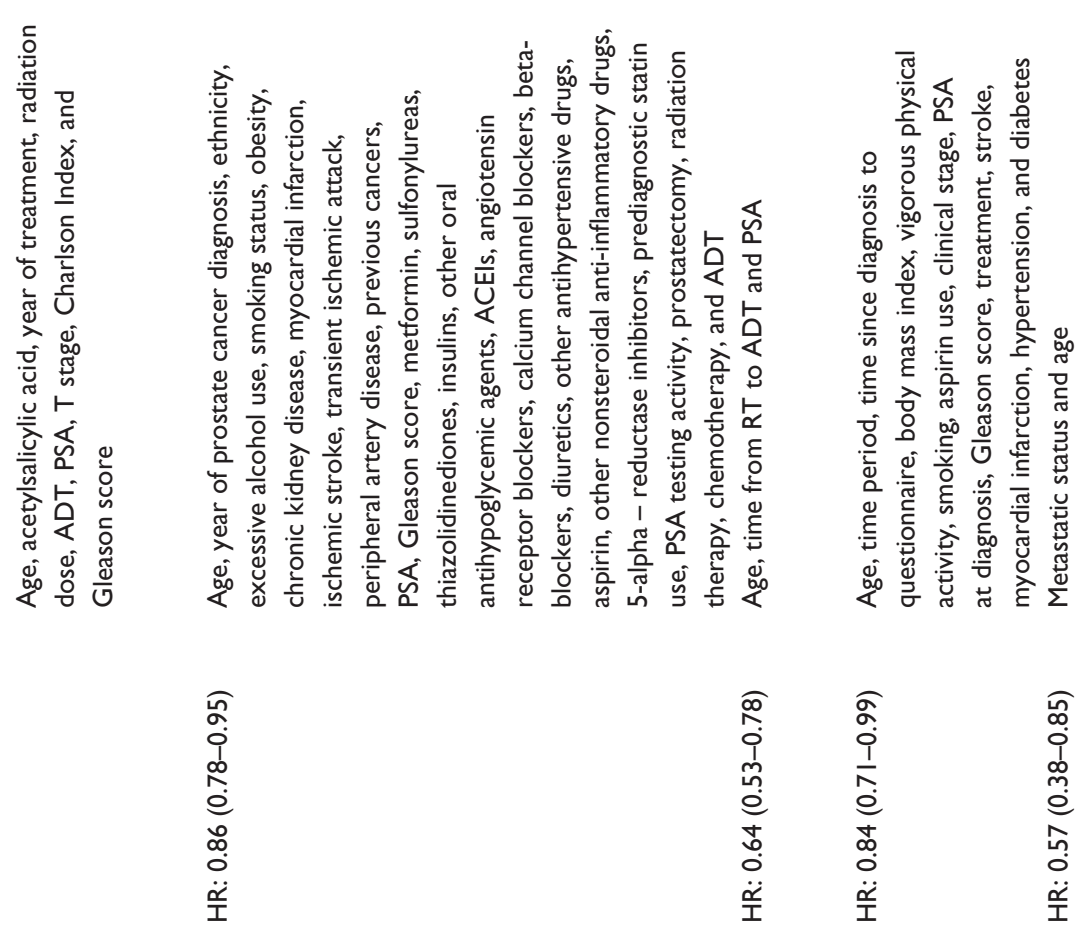

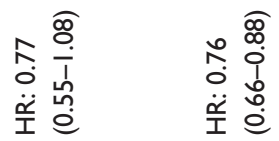

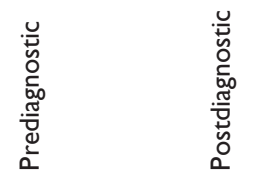

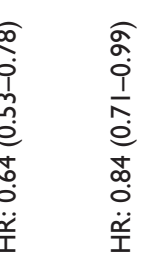

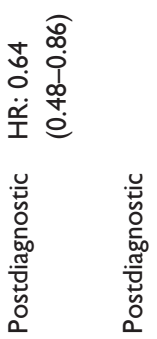

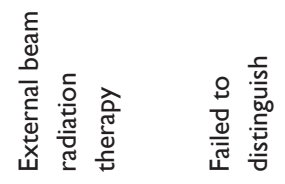

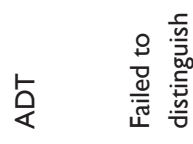
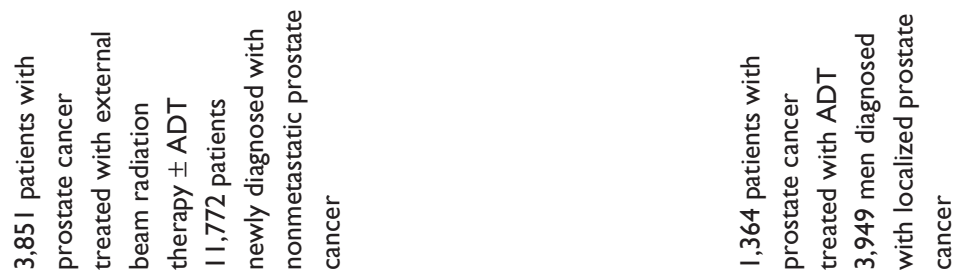

$\begin{array}{ll}\frac{1}{0} & \frac{1}{0} \\ \frac{5}{0} & \frac{5}{0}\end{array}$

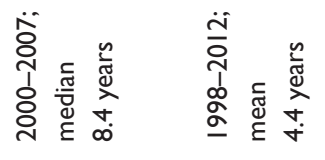

$\frac{\pi}{\pi}$

$\begin{array}{ll}\frac{t}{0} & \frac{ \pm}{0} \\ \frac{5}{0} & \frac{5}{0} \\ ن & U\end{array}$

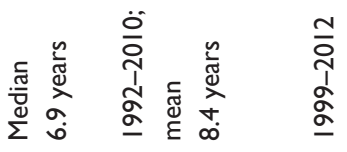

능 ำ ำ

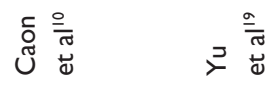

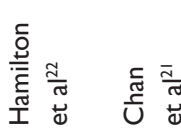

ำ 
Table 2 Main results of meta-analysis for the effect of statin use on ACM and PCSM

\begin{tabular}{|c|c|c|c|c|c|c|c|c|}
\hline \multirow[t]{2}{*}{ Statin use } & \multirow[t]{2}{*}{ Mortality } & \multirow[t]{2}{*}{ Groups/subgroups } & \multirow[t]{2}{*}{ Studies, $\mathbf{n}$} & \multicolumn{2}{|c|}{ Heterogeneity test } & \multicolumn{3}{|c|}{ Pooled risk estimates } \\
\hline & & & & $P^{2}(\%)$ & $P$-value & HR & $95 \% \mathrm{Cl}$ & $P$-value \\
\hline $\begin{array}{l}\text { Prediagnostic } \\
\text { statin use }\end{array}$ & $\mathrm{ACM}$ & Overall & 2 & 0 & 0.77 & 0.56 & $0.38-0.83$ & 0.003 \\
\hline Postdiagnostic & $\mathrm{ACM}$ & Overall & 7 & 72 & 0.002 & 0.77 & $0.69-0.87$ & $<0.001$ \\
\hline \multirow[t]{4}{*}{ statin use } & & Local therapy & 2 & 53 & 0.14 & 0.46 & $0.28-0.77$ & 0.003 \\
\hline & & $\begin{array}{l}\text { Failed to distinguish primary } \\
\text { treatment }\end{array}$ & 3 & 22 & 0.28 & 0.81 & $0.77-0.84$ & $<0.001$ \\
\hline & & Androgen deprivation therapy & I & - & - & 0.64 & $0.53-0.78$ & $<0.001$ \\
\hline & & Chemotherapy & I & - & - & 0.97 & $0.72-1.23$ & 0.80 \\
\hline Prediagnostic & PCSM & Overall & 6 & 77 & $<0.001$ & 0.53 & $0.36-0.77$ & 0.001 \\
\hline \multirow[t]{3}{*}{ statin use } & & Androgen deprivation therapy & I & - & - & 0.53 & $0.29-0.98$ & 0.043 \\
\hline & & Local therapy & 2 & 61 & 0.11 & 0.52 & $0.17-1.58$ & 0.25 \\
\hline & & $\begin{array}{l}\text { Failed to distinguish primary } \\
\text { treatment }\end{array}$ & 3 & 88 & $<0.001$ & 0.44 & $0.20-0.95$ & 0.04 \\
\hline Postdiagnostic & PCSM & Overall & 4 & 82 & $<0.001$ & 0.64 & $0.52-0.79$ & $<0.001$ \\
\hline \multirow[t]{2}{*}{ statin use } & & Androgen deprivation therapy & I & - & - & 0.64 & $0.48-0.86$ & 0.003 \\
\hline & & $\begin{array}{l}\text { Failed to distinguish primary } \\
\text { treatment }\end{array}$ & 3 & 88 & $<0.001$ & 0.73 & $0.69-0.78$ & $<0.001$ \\
\hline
\end{tabular}

Abbreviations: ACM, all-cause mortality; $\mathrm{Cl}$, confidence interval; HR, hazard ratio; PCSM, prostate cancer-specific mortality.

0.69-0.78; $\left.P<0.01 ; I^{2}=88 \%\right)$ and also showed a significant correlation.

\section{Discussion}

The main results of the present meta-analysis are as follows: 1) both pre- and postdiagnostic use of statins was associated with a decreased risk of ACM and PCSM, 2) postdiagnostic use of statins had a 0.4 -fold lower risk of ACM in patients with PCa who were treated with local therapy, and 3) both pre- and postdiagnostic use of statins was correlated with a significantly lower risk of PCSM in patients who were treated with androgen deprivation therapy.

Statins are commonly used to reduce cholesterol levels and are associated with a decrease in the prevalence of cardiovascular events, but the impact of statins on the prognosis of patients with PCa is still controversial.

\begin{tabular}{|c|c|c|c|c|c|c|c|c|c|c|}
\hline Study/subgroup & $\begin{array}{l}\text { Log } \\
\text { (hazard ratio) }\end{array}$ & SE & $\begin{array}{l}\text { Weight } \\
(\%)\end{array}$ & $\begin{array}{l}\text { Hazard ratio IV, } \\
\text { random, } 95 \% \mathrm{Cl}\end{array}$ & \multicolumn{2}{|l|}{ Year } & \multicolumn{3}{|c|}{$\begin{array}{l}\text { Hazard ratio IV, } \\
\text { random, } 95 \% \mathrm{CI}\end{array}$} & \\
\hline Geybels et al ${ }^{14}$ & -0.7985 & 0.7636 & 6.7 & $0.45(0.10-2.01)$ & 2013 & & & & & \\
\hline Calais Da Silva et al ${ }^{20}$ & -0.5651 & 0.2054 & 93.3 & $0.57(0.38-0.85)$ & 2015 & & & & & \\
\hline Total $(95 \% \mathrm{Cl})$ & & & 100 & $0.56(0.38-0.83)$ & & & & & & \\
\hline $\begin{array}{l}\text { Heterogeneity: } \chi^{2}=0.09 \\
\text { Test for overall effect: } z\end{array}$ & $\begin{array}{l}, d f=1(P=0.77) ; I \\
Z=2.93(P=0.003)\end{array}$ & $I^{2}=0 \%$ & & & & $\frac{1}{0.2}$ & 0.5 & 1 & 2 & $\begin{array}{l}+ \\
5\end{array}$ \\
\hline Study/subgroup & $\begin{array}{l}\text { Log } \\
\text { (hazard ratio) }\end{array}$ & SE & $\begin{array}{l}\text { Weight } \\
(\%)\end{array}$ & $\begin{array}{l}\text { Hazard ratio IV, } \\
\text { random, } 95 \% \mathrm{Cl}\end{array}$ & Year & & & & $\begin{array}{l}\mathrm{IV} \\
\mathrm{O} \mathrm{CI}\end{array}$ & \\
\hline Katz et al ${ }^{6}(\mathrm{RP})$ & -1.0498 & 0.2664 & 4.1 & $0.35(0.21-0.59)$ & 2010 & 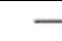 & - & & & \\
\hline Katz et al ${ }^{6}(\mathrm{RT})$ & -0.5276 & 0.2381 & 5.0 & $0.59(0.37-0.94)$ & 2010 & & & & & \\
\hline Niraula et $\mathrm{al}^{9}$ & -0.0305 & 0.1212 & 12.4 & $0.97(0.76-1.23)$ & 2013 & & & & & \\
\hline Yu et al ${ }^{19}$ & -0.1508 & 0.0498 & 22.0 & $0.86(0.78-0.95)$ & 2014 & & & - & & \\
\hline Dehlendorff et al ${ }^{17}$ & -0.2357 & 0.0252 & 24.9 & $0.79(0.75-0.83)$ & 2014 & & & & & \\
\hline Hamilton et $\mathrm{al}^{22}$ & -0.4463 & 0.1009 & 14.8 & $0.64(0.53-0.78)$ & 2015 & & & & & \\
\hline Chan et $\mathrm{al}^{21}$ & -0.1744 & 0.0858 & 16.8 & $0.84(0.71-0.99)$ & 2015 & & & & & \\
\hline Total $(95 \% \mathrm{Cl})$ & & & 100 & $0.77(0.69-0.87)$ & & & & & & \\
\hline $\begin{array}{l}\text { Heterogeneity: } \tau^{2}=0.01 \\
\text { Test for overall effect: }\end{array}$ & $\begin{array}{l}; \chi^{2}=21.32, d f=6( \\
z=4.42(P<0.0000\end{array}$ & $\begin{array}{l}(P=0.002) \\
1)\end{array}$ & $; I^{2}=72 \%$ & & & $\frac{1}{0.2}$ & 0.5 & 1 & 2 & $\frac{1}{5}$ \\
\hline
\end{tabular}

Figure 2 Pooled analyses for the effect of prediagnostic (A) and postdiagnostic (B) statin use on all-cause mortality of prostate cancer.

Abbreviations: $\mathrm{Cl}$, confidence interval; $d f$, degrees of freedom; RP, radical prostatectomy; RT, radiotherapy; SE, standard error. 


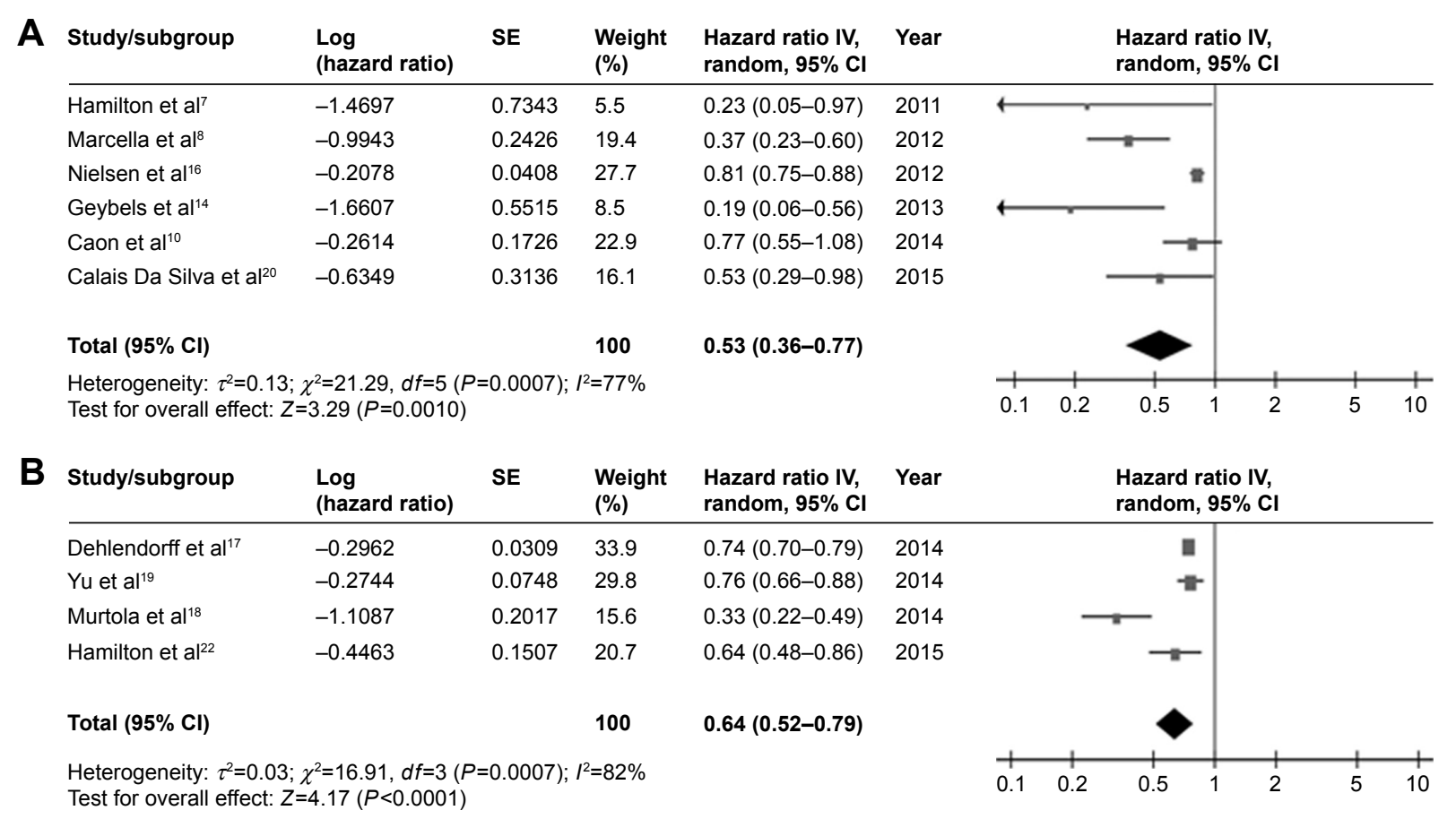

Figure 3 Pooled analyses for the effect of prediagnostic (A) and postdiagnostic (B) statin use on prostate-cancer-specific mortality of prostate cancer. Abbreviations: $\mathrm{Cl}$, confidence interval; $d f$, degrees of freedom; SE, standard error.

However, in this study, we demonstrated that statins were associated with a decreased risk of both ACM and PCSM in patients with PCa, and this finding is supported by an observational study of 295,925 patients, which reported a decreased rate of cancer-related mortality among patients who took statins. ${ }^{16}$

Several factors may account for the beneficial impact of statins on ACM and PCSM. 1) Cholesterol is required for basic cellular functions, including maintenance of membrane integrity and involvement of signaling pathways, which are critical for cancer cell proliferation, ${ }^{23-25}$ thus a decrease in cholesterol level might reduce PCa growth. 2) Previous experimental studies have demonstrated that statins may have anti-inflammatory, proapoptotic, and antiangiogenic effects, which may reduce metastasis and invasiveness. ${ }^{26,27} \mathrm{~A}$ recent meta-analysis demonstrated that statins were associated with a lower risk of $\mathrm{PCa}$ recurrence in patients who were treated with radiotherapy. 3) Cholesterol is a precursor of androgens; thus, a reduction in cholesterol level leads to a decrease in testosterone and dihydrotestosterone, which are crucial to androgen receptor, ${ }^{28,29}$ and a reduction in androgen receptor may predict PCa outcome. ${ }^{30}$ In line with this, the study suggests that both pre- and postdiagnostic use of statins is correlated with a significantly lower risk of PCSM in patients who were treated with androgen deprivation therapy. This phenomenon has also been seen in patients with breast cancer. ${ }^{31}$

Additionally, Nielsen et $a 1^{16}$ revealed the absence of a dose-dependent effect of statins, while Yu et al $^{19}$ found that long-term treatment with statins provided greater benefit than short-term treatment. Therefore, randomized trials are needed to investigate the effect of statins on ACM and PCSM, especially with regard to dose and time dependency.

Several limitations should be taken into consideration when interpreting our results. First, we found between-study heterogeneity in the meta-analysis, which might affect the strength of the results in the study. However, we performed subgroup analyses to explore the source of heterogeneity when we could not find it. Second, we did not evaluate the effect of postdiagnostic statin use on the association between prediagnostic statin use and patient survival because of limited data from included studies. We therefore evaluated postdiagnostic statin use, without taking into account the effect of prediagnostic statin use.

\section{Conclusion}

Both pre- and postdiagnostic use of statins is associated with better overall survival and cancer-specific survival. Randomized controlled trials are needed to further assess 
the effect of statin use on the mortality of patients with $\mathrm{PCa}$ in the future.

\section{Acknowledgment}

We are grateful to all our colleagues in the Department of Urology, West China Hospital of Sichuan University, for their help in this study.

\section{Disclosure}

The authors report no conflicts of interest in this work.

\section{References}

1. Eisenberg DA. Cholesterol lowering in the management of coronary artery disease: the clinical implications of recent trials. Am J Med. 1998;104(2A):2S-5S.

2. Wong WW, Dimitroulakos J, Minden MD, Penn LZ. HMG-CoA reductase inhibitors and the malignant cell: the statin family of drugs as triggers of tumor-specific apoptosis. Leukemia. 2002;16(4):508-519.

3. Dulak J, Jozkowicz A. Anti-angiogenic and anti-inflammatory effects of statins: relevance to anti-cancer therapy. Curr Cancer Drug Targets. 2005;5(8):579-594.

4. Carlberg M, Dricu A, Blegen H, et al. Mevalonic acid is limiting for $\mathrm{N}$-linked glycosylation and translocation of the insulin-like growth factor-1 receptor to the cell surface. Evidence for a new link between 3-hydroxy-3-methylglutaryl-coenzyme a reductase and cell growth. J Biol Chem. 1996;271(29):17453-17462.

5. Bansal D, Undela K, D'Cruz S, Schifano F. Statin use and risk of prostate cancer: a meta-analysis of observational studies. PLoS One. 2012;7(10): 466691.

6. Katz MS, Carroll PR, Cowan JE, Chan JM, D'Amico AV. Association of statin and nonsteroidal anti-inflammatory drug use with prostate cancer outcomes: results from CaPSURE. BJU Int. 2010;106(5): 627-632.

7. Hamilton R, Vijai J, Gallagher D, et al. Analysis of statin medication, genetic variation and prostate cancer outcomes. J Urol. 2011;(1):e401.

8. Marcella SW, David A, Ohman-Strickland PA, Carson J, Rhoads GG. Statin use and fatal prostate cancer: a matched case-control study. Cancer. 2012;118(16):4046-4052.

9. Niraula S, Pond G, de Wit R, Eisenberger M, Tannock IF, Joshua AM. Influence of concurrent medications on outcomes of men with prostate cancer included in the TAX 327 study. Can Urol Assoc J. 2013; 7(1-2):E74-E81.

10. Caon J, Paquette M, Hamm J, Pickles T. Does statin or ASA affect survival when prostate cancer is treated with external beam radiation therapy? Prostate Cancer. 2014;2014:184297.

11. Liberati A, Altman DG, Tetzlaff J, et al. The PRISMA statement for reporting systematic reviews and meta-analyses of studies that evaluate healthcare interventions: explanation and elaboration. $B M J$. 2009;339:b2700.

12. Lo CK, Mertz D, Loeb M. Newcastle-Ottawa Scale: comparing reviewers' to authors' assessments. BMC Med Res Methodol. 2014;14:45.
13. Seisen T, Granger B, Colin P, et al. A systematic review and metaanalysis of clinicopathologic factors linked to intravesical recurrence after radical nephroureterectomy to treat upper tract urothelial carcinoma. Eur Urol. 2015;67(6):1122-1133.

14. Geybels MS, Wright JL, Holt SK, Kolb S, Feng Z, Stanford JL. Statin use in relation to prostate cancer outcomes in a population-based patient cohort study. Prostate. 2013;73(11):1214-1222.

15. Higgins JP, Thompson SG, Deeks JJ, Altman DG. Measuring inconsistency in meta-analyses. BMJ. 2003;327(7414):557-560.

16. Nielsen SF, Nordestgaard BG, Bojesen SE. Statin use and reduced cancer-related mortality. N Engl J Med. 2012;367(19):1792-1802.

17. Dehlendorff C, Skriver C, Jespersen CG, et al. Use of statins and prostate cancer mortality. Pharmacoepidemiol Drug Saf. 2014;23:354.

18. Murtola T, Maattanen L, Taari K, Tammela T, Auvinen A. Statin use and survival after prostate cancer diagnosis in the Finnish prostate cancer screening trial. $J$ Urol. 2014;(1):e832.

19. Yu O, Eberg M, Benayoun S, et al. Use of statins and the risk of death in patients with prostate cancer. J Clin Oncol. 2014;32(1):5-11.

20. Calais Da Silva F Jr, Calais Da Silva F Sr, Goncalves F, et al. Effects of prior use of statins in a phase 3 study of intermittent monotherapy versus continuous combined androgen deprivation. Eur Urol Suppl. 2015; 14(2):e563.

21. Chan JM, Kenfield SA, Paciorek A, Platz EA, Giovannucci EL, Stampfer M. Post-diagnostic statin use and the risk of lethal prostate cancer in the health professionals follow-up study. Cancer Epidemiol Biomarkers Prev. 2015;24(10):1638-1640.

22. Hamilton R, Ding K, Crook J, et al. The association between statin use and outcomes in patients initiating androgen deprivation therapy. J Urol. 2015;(1):e930.

23. Chan KKW, Oza AM, Siu LL. The statins as anticancer agents. Clin Cancer Res. 2003;9(1):10-19.

24. Wong WWL, Dimitroulakos J, Minden MD, Penn LZ. HMG-CoA reductase inhibitors and the malignant cell: the statin family of drugs as triggers of tumor-specific apoptosis. Leukemia. 2002;16(4):508-519.

25. Cattarino S, Seisen T, Drouin SJ, et al. Influence of statin use on clinicopathological characteristics of localized prostate cancer and outcomes obtained after radical prostatectomy: a single center study. Can J Urol. 2015;22(2):7703-7708.

26. Fritz G. HMG-CoA reductase inhibitors (statins) as anticancer drugs (review). Int J Oncol. 2005;27(5):1401-1409.

27. Chao C, Jacobsen SJ, Xu L, Wallner LP, Porter KR, Williams SG. Use of statins and prostate cancer recurrence among patients treated with radical prostatectomy. BJU Int. 2013;111(6):954-962.

28. Roy M, Kung H-J, Ghosh PM. Statins and prostate cancer: role of cholesterol inhibition vs. prevention of small GTP-binding proteins. Am J Cancer Res. 2011;1(4):542-561.

29. Papadopoulos G, Delakas D, Nakopoulou L, Kassimatis T. Statins and prostate cancer: molecular and clinical aspects. Eur J Cancer. 2011; 47(6):819-830.

30. Stelloo S, Nevedomskaya E, van der Poel HG, et al. Androgen receptor profiling predicts prostate cancer outcome. EMBO Mol Med.2015; 7(11):1450-1464.

31. Mafuvadze B, Liang Y, Hyder SM. Cholesterol synthesis inhibitor RO 48-8071 suppresses transcriptional activity of human estrogen and androgen receptor. Oncol Rep. 2014;32(4):1727-1733.
OncoTargets and Therapy

\section{Publish your work in this journal}

OncoTargets and Therapy is an international, peer-reviewed, open access journal focusing on the pathological basis of all cancers, potential targets for therapy and treatment protocols employed to improve the management of cancer patients. The journal also focuses on the impact of management programs and new therapeutic agents and protocols on

\section{Dovepress}

patient perspectives such as quality of life, adherence and satisfaction. The manuscript management system is completely online and includes a very quick and fair peer-review system, which is all easy to use. Visit http://www.dovepress.com/testimonials.php to read real quotes from published authors. 